\title{
Thomas Lundmark, Charting the Divide Between Common and Civil Law (Oxford University Press 2012) 465 pages
}

\author{
By Attila Badó and Samantha Joy Cheesman
}

Anyone who has ever tried to teach comparative law as an individual subject, will have been faced with the fundamental question (which is not obvious in all areas of the law) of what can be important for students in order to grab their attention. When considering the above statement we can see an internal struggle. There is a general consensus of the necessity to teach the subject and at the same time the independent characteristic of comparative law is continuously questioned. And to top it all off, unlike most of the other fields of law which have uncertain status the doubts are raised by the comparative lawyers themselves. As Thomas Lundmark states, this self doubt penetrates comparative law from the beginning. For those who are already tired of the "Method-Science - Discipline" debate this book can be a refreshing experience. Additionally part of its academic novelty is that the book can be very helpful for those who venture into teaching comparative law. Compared to literary works which confine themselves to the general introduction to the most important legal systems of the world, Lundmark sheds light on the most important questions of comparative law by analyzing 4 countries legal cultures whom he knows well and also speaks the language of all of them.

The book starts with a helpful in-depth comparison of four particular countries, Germany, Sweden, England and Wales, and the United States of America. The author identifies four main areas which are employed to compare the various jurisdictions,

1. linguistic,

2. how law is conceived of,

3. primary actors and

4. how to deal with legal rules.

The author asserts that the study of comparative law is a relatively new area of study as such the question what is the role of comparative law has yet to be fully answered. As such Lundmark in his book sets out to propose answers for this question. The historical development of the importance and shifting of emphasis of comparative law can be traced back to the WW's. After WWI international cooperation in legal matters was necessary so as to find common solutions. However, after WWII comparative legal study was utilized to study legal traditions as well as cultures.

The author poses the question about the appropriateness of the labels attributed to the different legal families. Over nine chapters Lundmark sets out the case for the fact that the supposed divide between the legal disciplines actually have more common ground and this is growing closer due to the importance of the Court of Justice of the European Union (CJEU) in harmonizing legal rules. The CJEU illustrates the slow convergence that is already occurring in E.U. law. This "circle of convergence", that the author refers to is completed when the national courts start to take into consideration the jurisprudence of the CJEU in reaching their own decisions. This leads into the argument that comparative law is ultimately searching for an unification of laws. Consequently, Lundmark warns the reader 
that as they seek this unification of laws that they must not fall into the common trap of approximating laws and simply transplanting them into their own or other legal jurisdictions without any consideration of the sociological and political factors.

As a textbook Lundmark sets out helpful guidelines for scholars of comparative law to use when analyzing different laws or legal systems. Lundmark refers to these three steps as, the Why, the How and the What. These three steps are interconnected which are impossible to separate in practice. The author then uses his own tools throughout the book illustrating how they can be best used to demonstrate the way in which a comparative methodology can be used.

In addition to his three steps for using comparative law Lundmark also states that the purpose of comparative law is threefold. It is namely the improvement of one's own law, the harmonization or uniformity of law and then finally the search for universal commonalities as well as the very apparent differences. These for Lundmark are essentially the core of comparative law study.

The chapters in the book helpfully walk the student through the key arguments of the various comparative lawyers regarding comparative legal linguistics, the role of lawyers, judges, the lay jurists, legal reasoning, statutes and their construction as well as precedents.

The linguistic analysis plainly explains the basic translation difficulties, however, in order to appreciate this there is the presumption that the reader also speaks at least 3 languages. Particularly the interconnection between language and predictability points out the differences between the legal systems.

The didactical novelty, is that the author explains very logically through the analysis of the comparative jurisprudence to the reader how important the theoretical frameworks are for the comparison of the different legal systems. It can be debated how the author narrowed the legal theoretical discourse to three legal schools (legal positivism, natural law, legal realism) but from Lundmarks perspective it is evident why this decision was made. Those who teach legal theory understand well that students can easily lose their way amongst the different theoretical schools of thought and this results in them having no appreciation and a lack of basic knowledge.

We are of the opinion that the most important chapters are those contained under the heading of Legal Actors. These chapters are very well structured and this topic, by the way, can also pique the interest of students everywhere. The book caters the reader with up-todate knowledge of the important actors of the judiciary of the four countries.

It is the last three chapters (legal reasoning, statutes and their construction and precedents) where the student can truly grasp the ingrained mis-characterizations that are prevalent in comparative law study. Lundmark provides a helpful example of how the search for the norm or "Normsuche" in each jurisdiction is achieved. By doing so he illustrates that the mental processes are identical in England and Wales, Sweden and the United States of America. Additionally, no substantive practical difference between the systemization of Germany, England and Wales and American law. When considering the construction of statutes Lundmark observes that despite the obvious differences between England and the three other countries there do exist similarities with Sweden as neither country adopted the Roman law model which Germany did resulting in a drive for codification which the former two never really experienced. Here a divide is apparent between the four countries with Germany and the U.S. being grouped together because of the active role that the courts play in interpreting and applying the "constitutionality of legislation.", and the U.K. and Sweden. 
Regarding the matter of precedent an interesting observation is made that both Germany and the Sweden provide statutory provisions that impose vertical respect for precedent. Additionally the U.K. has a statutory provision that the British courts adhere to the legal principles announced in the case decisions of the CJEU. Unlike England and Wales, and the U.S. (which both use the historical method of precedent) Germany applies the "formalistic textual manner."

To summarize we can say that an interesting, informative usable new textbook was born from the pen of Thomas Lundmark, under the care of the Oxford Publishers. Additionally, we recommend this book to all of those who have struggled with teaching comparative law as well as to all who want to expand their knowledge of the four examined countries. 